\title{
Manufacturing Outsourcing to Achieve Organizational Performance through Manufacturing Integrity Capabilities
}

\author{
Muralitharan Shanmugan¹, Muhammad Shabir Shaharudin², \\ Yuvaraj Ganesan1, and Yudi Fernando² \\ ${ }^{1}$ Graduate School of Business, Universiti Sains Malaysia, 11800, Penang, Malaysia \\ ${ }^{2}$ Faculty of Industrial Management, Universiti Malaysia Pahang, Lebuhraya Tun Razak, 26300 \\ Gambang, Pahang, Malaysia
}

\section{Abstract}

Manufacturing companies outsource their manufacturing process to achieve organizational performance. Companies can focus on improving their core business processes while leaving manufacturing process to companies that are more efficient and cost-effective. However, this leaves manufacturing companies with a dilemma as those outsourcing companies are also producing for competitors and companies' brand

Corresponding Author: Muralitharan Shanmugan shabir.shaharudin@gmail.com

Received: 5 August 2019 Accepted: 14 August 2019 Published: 18 August 2019

Publishing services provided by Knowledge

(c) Muralitharan Shanmugan et al. This article is distributed under the terms of the

commons Attribution License, which permits unrestricted use and redistribution provided that the original author and source are credited.

Selection and Peer-review unde the responsibility of the FGIC2019 Conference Committee.

\section{G OPEN ACCESS}

is liable to the integrity of outsourcing companies. By having integrity capabilities, it is argued that companies can achieve organizational performance. This paper investigates the relationship between manufacturing outsourcing and organizational performance with the mediating effect of manufacturing integrity capabilities. This paper contributes to the body of literature by investigating the impact of manufacturing integrity capabilities with resource-based view and transaction cost economics theories. Furthermore, this paper also is practically useful for companies to understand integrity capabilities that are useful to increase organizational performance in the era of the dynamic business environment.

Keywords: manufacturing performance, manufacturing capability, manufacturing outsourcing, resource-based view, conceptual paper.

\section{Introduction}

Integrity in operations is a critical issue in the manufacturing industry. This is due to the hypercompetitive market and complex customer requirements. While companies try to sustain in the business by engaging in the supply chain with other companies, part of that business also involves outsourcing part of the supply chain process or capabilities. Thus, when a company involved in shady business strategy or unethical issue deemed by society, not only that company but the whole supply chain will be affected. For example, Foxconn, a Chinese company producing electronic products for Apple from the United States of America, had trouble with its handling of employee suicide case. 
As a result, Apple organizational performance was also affected due to consumers' backlash. That is the reason why it is important for companies in the supply chain to protect and uphold its integrity.

Companies all over the world have shown interest in upholding the integrity and extend it to its supply chain partners (Cherrafi, Elfezazi, Chiarini, Mokhlis, \& Benhida, 2016). Due to that, each supply chain partner has guarded its integrity capabilities to ensure that the networks or alliances remain strong and overall performance can be expected. Integrity capabilities in manufacturing are ensuring highest standards in every aspect of companies' operations such as quality, cost-effective, flexibility and responsiveness without neglecting responsibilities toward its stakeholders (Gunasekaran, Subramanian, \& Rahman, 2015). Ensuring integrity capabilities among manufacturing companies are critical because manufacturing has a complex and vast network of the supply chain. Nowadays, with outsourcing among manufacturers becoming a norm in the industry, the complexity of ensuring integrity (Srinivasan, Giannikas, Kumar, Guyot, \& McFarlane, 2018) capabilities have become more challenging. Integrity capabilities are difficult to manage as outsourcing companies produce mass products for multiple companies and even for competitors (Wu, Yang, \& Olson, 2018). This has raised issues among companies that its product design and features might be at risk (Liu, Blome, Sanderson, \& Paulraj, 2018). This will lead to negative organizational performance.

On the other hand, society is a concern that companies might shift the blame when there is an issue to outsourcing companies (Liu et al., 2018). Also, companies might collide with each other becoming too big to fall and dictate terms and product offering to consumers (Fu, Kok, Dankbaar, Ligthart, \& van Riel, 2018). This will lead to a lower choice of products and unacceptable performance by companies to offer good products. Therefore, outsourcing companies need to ensuring integrity capabilities to achieve organizational performance (Ali, Tan, \& Ismail, 2017).

In Malaysia, the performance of manufacturing companies is important. This is because the manufacturing industry in Malaysia is one of the most developed in the ASEAN region (Rusli, Rahman, \& Ho, 2012). Having said that, there are vast companies, whether international or local, that participate in the global supply chain. As a result, it ties the performance of the overall supply chain with each company's performance. Companies that are unable to increase or sustain their organizational performance will drag other supply chain companies down (Saeidi, Sofian, Saeidi, Saeidi, \& Saaeidi, 2015). This is a critical issue in the industry as Malaysian manufacturing companies are producers for other companies or in other words, an outsource company for another company locally or globally. Without integrity capabilities, both local and global 
companies will seek other outsource companies that can ensure their companies remain competitive and perform well.

Nevertheless, Malaysia manufacturing industry is still lagging in terms of technological advancement and adoption of better operational excellence criteria such as flexibility due to its practice ties to the demand of its customer rather than undertakes its own decision in operational improvement (Fernando, Wah, \& Shaharudin, 2016). The low value-added Malaysian manufacturing industry is directly linked to the weak development of new product and technology cluster (Ahmad, Mohammad, Maidin, Zainol, \& Noor, 2013). Despite this industry is performing excellent in the past two decades, the manufacturing industry in Malaysia confronted substantial challenges in sustaining growth (Shaharudin \& Fernando, 2015). Improvement in organizational performance can contribute to the sustainability of growth. This is because the improvement in organizational performance will directly increase productivity and reduce the production cost. Outsourcing is one method to reduce manufacturing or production cost. This approach will have a positive impact on organizational performance (Wang \& He, 2018). Also, Malaysian American Electronics Industry reported that manufacturing companies faced gaps in their outsourcing practices (Hassan, Razali, \& Talib, 2015) as these companies were not able to rise local sourcing by 50 percent and being inflexible to customer needs, despite substantial investment by companies and government agencies. By increasing the local sourcing, the manufacturing cost of the product can be reduced, and this will translate the effect of overall organization performance in term of revenue. These arguments show that manufacturing outsourcing performance in Malaysia needs improvement (Hassan et al., 2015; Karim, Smith, Halgamuge, \& Islam, 2008). In the survey done by Deloitte (2016) on global manufacturing competitiveness index, Malaysia position in 17th place below Thailand in 2016 and expected to move to rank 13 below Vietnam in 2020. Thailand and Vietnam are emerging economy countries as Malaysia. The competitiveness index showed the result of the organizational performances of that has a direct relationship with the manufacturing performance (Galankashi, Memari, Anjomshoae, Ma’aram, \& Helmi, 2014). Following that, Malaysia needs to improve its competitiveness by ensuring more companies in achieving organizational performance and adopting integrity capabilities (Padhi, Pati, \& Rajeev, 2018). On the other hand, integrity capabilities have been widely accepted in the literature to increase the performance of the company. However, limited studies on the empirical evidence on whether integrity capabilities are improving organizational performance and whether it has an impact on outsourcing practice (Giovanni, 2012; Shi et al., 2019; Yin, Zhao, Xi, \& Zhang, 2018). 
This study objective is to address these issues by providing empirical evidence and theory alignment so that it can contribute to the literature. Also, companies can achieve organizational performance by practicing outsourcing and focusing on integrity capabilities. This paper is divided into four sections; introduction, literature review to discuss current knowledge regarding organizational performance, outsourcing, and integrity capabilities. This will follow with methodology and expected the outcome of the study.

\section{Literature Review}

\subsection{Organizational Performance}

Organizational performance can be defined as the ability of companies to meet stakeholders' requirements and achieving competitive advantage (Gunasekaran \& Ngai, 2012). In today's dynamic competitive environment, companies are not only responsible for improving their operational performance but overall performance, including economic, environmental, and social (Zhu, Sarkis, \& Lai, 2013). Even though the environment and society are becoming more important, the company's performance has been consistently evaluated through the lens of its success in operations and economic profits (Fernando, Jasmi, \& Shaharudin, 2019). As a result, financial measures are critical for the evaluation of organizational performance. Economic, financial measures include return on assets ( $R O A)$, return on investments (ROI), return on equity (ROE), market share, sales and profitability of the business (Jasmi \& Fernando, 2018). Increasing the performance of manufacturing companies is important due to the manufacturing industry plays an important role in the economy ( Jabbour, Frascareli, \& Jabbour, 2015). Malaysia, the thirdlargest economy in South East Asia and the 29th largest in the world, is emerging as one of the most stable economies in the Asian region with its manufacturing industry being one of the most well-developed in ASEAN region (Department of Statistics Malaysia, 2018b). Its GDP has been growing steadily for the last 10 years at five to six percent. (MIDA, 2017). Manufacturing activity is an important factor in the economy due to its contribution to GDP external trade and job creation. Based on the contribution of the manufacturing industry, the GDP trend is increasing (Department of Statistics Malaysia, 2018a). This shows the importance of ensuring that manufacturing companies continue to perform as it has a high impact on the economy. 


\subsection{Manufacturing Outsourcing}

Manufacturing outsourcing can be defined as production process of company undertaken by another company that is specialize in manufacturing product that results in benefits such as cost reduction, efficient process, more technological advance process and technology and better yield of product (Bigliardi \& Bottani, 2010; Kamalahmadi \& Parast, 2016; Liu et al., 2018). Nowadays, with competition intensifies, companies are looking for supply chain partner that would be able to improve its efficiency in the production of products so that it can sustain in the business and achieve better performance (Zhang, Wang, Yin, \& Su, 2012). As a result, manufacturing outsourcing has become critical and norm among companies in the manufacturing industry. Nevertheless, outsourcing to other company needs to be taken seriously as it also impacts on the brand and performance of the company (Cherrafi et al., 2016). Scholars have long found that collaboration and integration of the production process in supply chain networks are important (Padhi et al., 2018). However, specific outsourcing studies about improving organizational performance is still scarce (Zhu et al., 2013). This is due to many outsourcing companies are in a developing country, and the response rate from developing countries companies are limited. Therefore, an investigation of organizational performance from the perspective of outsourcing companies are empirically needed to contribute to the literature. On the other hand, companies are not solely outsourcing its production process, but companies also outsource its key activities or processes such as information technology, marketing, customer service, distribution network and logistics (Gunasekaran, Subramanian, \& Ngai, 2019; Gunasekaran et al., 2015). Due to that, companies can focus on their core business and contribute to the overall organizational performance.

\subsection{Integrity Capabilities}

Integrity capabilities refer to the ability of a company to ensure that the product or service offered is consistent with the norms and expectations of its stakeholders (Biesenthal, Clegg, Mahalingam, \& Sankaran, 2018; Zhu et al., 2013). Externally, integrity capabilities also serve as an unwritten agreement between the company with other companies in the same industry to better serve its customer by adopting selected criteria that are deemed important by stakeholders. In that sense, quality, cost reduction, the flexibility of the company, and responsiveness to address stakeholders' demand are expected by stakeholders (Gunasekaran et al., 2015). It has been found that integrity capabilities 
enable companies to achieve their operational performance and contribute to the overall organizational performance.

\subsection{Resource-Based View Theory}

This study underlined theory is derived from the resource-based view theory (RBV). This theory considers company competitive advantage as a result of company performance in managing its resources and innovation (Liu et al., 2018; Padhi et al., 2018). Also, companies that can improve their supply chain process to fully optimized their resources can achieve organizational performance. On the other hand, through the adoption of integrity capabilities that tap into company's ability to meet the operational performance will result in higher capabilities of companies to meet performance and stakeholders' requirements (Huo, Ye, Zhao, \& Shou, 2016). This study used of RBV can be explained in Figure 1 where manufacturing outsourcing is considered as an enabler for capitalizing on unique resources that help companies to achieve performance. Furthermore, with integrity capabilities, companies can distinguish its product or service offering better than its competitors. Thus, enabling the company to achieve better performance.

\subsection{Theoretical Framework}

Based on the literature review and research problems, an integrated framework is presented in Figure 1. The focus of the study is to investigate the organizational performance of manufacturing companies in Malaysia. The performance of manufacturing companies can be achieved or improved through practicing manufacturing outsourcing, and through the adoption of integrity capabilities, companies can obtain better performance. Thus, organizational performance serves as the dependent variable while manufacturing outsourcing and integrity capabilities serve as the independent variable and mediating variable in this study.

\subsection{Hypothesis Development}

\subsubsection{Manufacturing Outsourcing Activities and Organization Perfor- mance}

Manufacturing outsourcing has been found to contribute largely to the operational performance of a company (Wang \& He, 2018). Previous studies have found that companies involved in outsourcing to improve its performance that only happen when 


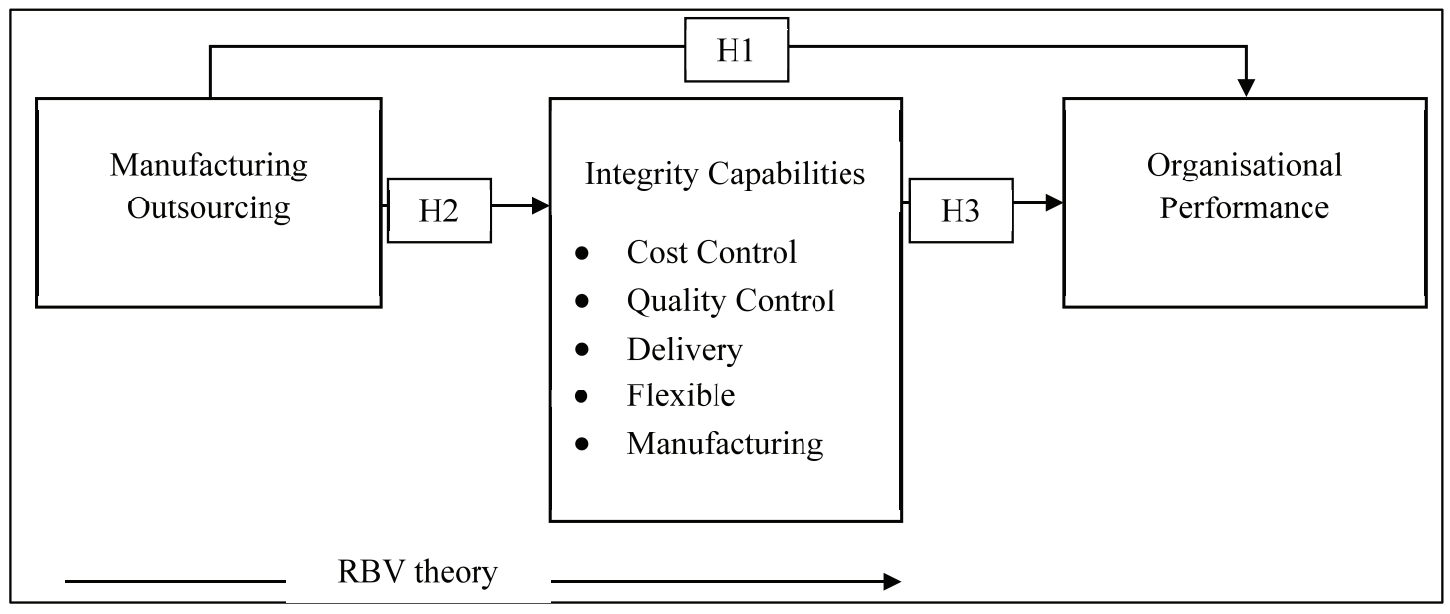

Figure 1: Theoretical Framework.

companies collaborate with other companies that are more efficient in certain business activities especially production process (Li, Su, \& Ma, 2017). Companies that outsource its production process or certain business activities are more likely to attain operational goals such as quality, cost reduction, flexibility, and responsiveness (Gunasekaran \& Ngai, 2012). Thus, it can be hypothesized that:

H1 Manufacturing outsourcing activities positively and significantly influence organization performance

\subsubsection{Manufacturing Outsourcing Activities and Integrity Capabilities}

Scholars have found that manufacturing outsourcing enables companies to achieve operational performance as there are vast companies that outsource its manufacturing process to other companies that are able to produce products at a cheaper price, better quality, more advance in production technology, have expertise that enable companies to produce sophisticated products and flexible in design and features of the product (Ahi, Jaber, \& Searcy, 2016; Allur et al., 2018; Dissanayake \& Cross, 2018; Huo et al., 2016; Tosarkani \& Amin, 2018). As a result, companies that outsource can meet stakeholders' requirements for quality, delivery, cost-effective, flexible, and responsive in its operations (Gunasekaran \& Ngai, 2012). This, in return, ensures consumers to put more trust and improve the company's integrity. Thus, it can be hypothesized that:

H2a Manufacturing Outsourcing activities positively influences Cost Control

H2b Manufacturing Outsourcing activities positively influences Quality Control

$\mathrm{H} 2 \mathrm{c}$ Manufacturing Outsourcing activities positively influences Delivery 
H2d Manufacturing Outsourcing activities positively influences Flexible Manufacturing

\subsubsection{Integrity Capabilities and Organization Performance}

Previous studies have found that operational performance leads to overall attainment in organizational performance (Gunasekaran \& Ngai, 2012; Zhu et al., 2013). Since companies need to first achieve its economic performance in terms of profits, companies tend to focus on improving its product offering to its customers. To improve the product offering, companies adopted several operational criteria such as cost reduction or cost control, the flexibility of its production process, responsiveness to customer demand, delivery of its promise to customers and producing a quality product. The operational criteria that companies adopt to ensure its customers that the product offering can meet customer requirements are known as integrity capabilities (Cherrafi et al., 2016; Wu et al., 2018; Shi et al., 2019; Yin et al., 2018). Scholars have found that there are two school of thought where scholars found that when companies achieve integrity capabilities are able to achieve economic performance including profits while the other school of thought found that when companies focus on economic performance, it increases the ability of companies to achieve other performances such as integrity capabilities, environment and social (Nishitani, Kokubu, \& Kajiwara, 2013; Zhu et al., 2013). Taken into consideration, both school of thoughts, it is believed that companies that adopt integrity capabilities can achieve organizational performance. Thus, it can be hypothesized that:

H3a Cost Control positively influences Organization Performance

H3b Quality Control positively influences Organization Performance

H3c Delivery positively influences Organization Performance

H3d Flexible Manufacturing positively influences Organization Performance

\subsubsection{Mediation effect of Integrity Capabilities on Manufacturing Out- sourcing Activities and Organizational Performance}

Companies that have high integrity that consumers trust or that has a good brand image will have good organizational performance (Cherrafi et al., 2016; Zhao, Zhao, Davidson, \& Zuo, 2012). This is because trust comes from the ability of companies to ensure its customers that it can deliver quality, cost-effective, responsive to the requirements of customers and able to be flexible. Since outsourcing has become a norm in the 
manufacturing industry, more companies are finding outsourcing companies to be part of their supply chain networks to improve its performance (Kamalahmadi \& Parast, 2016; Xiao, Yang, Zhang, \& Kuo, 2016). Finding good outsourcing companies are not the enabler to positive organizational performance but the ability of that company to have better integrity capabilities. Thus, it can be hypothesized that:

$\mathrm{H} 4 \mathrm{a}$ Cost Control mediate the relationship between Manufacturing Outsourcing Activities and Organization Performance

H4b Quality Control mediate the relationship between Manufacturing Outsourcing activities and Organization Performance

$\mathrm{H} 4 \mathrm{c}$ Delivery mediate the relationship between Manufacturing Outsourcing activities and Organization Performance

H4d Flexible Manufacturing mediate the relationship between Manufacturing Outsourcing activities and Organization Performance

\section{Methodology}

This study employs a quantitative methodology by performing statistical analysis. The population for this study is manufacturing companies as listed in the Federation of Malaysian Manufacturers (Federation of Malaysian Manufacturing, 2017) database. The sampling frame is Electric and Electronic (E\&E) companies registered with FMM database. This study uses stratified random sampling, and data collection is undertaken through the use of mail and e-survey (Google form) following the methodology of (Fernando et al., 2019). The unit of analysis is top management in E\&E companies. In this research, the survey questionnaires consist of five parts. There are $A$. Respondent Profile, B. Profile of the Organization, C. Organization Performance, D. Outsourcing Activity, E. Integrity Capabilities, and F. Additional Comments. The variables of the research study was measured on five-point Likert scale, i.e., (1) strongly disagree to (5) strongly agree, were organization performance and outsourcing activities. The variables which measured on seven-point Likert scale, i.e., (1) strongly disagree to (7) strongly agree were cost control, quality control, delivery, and flexible manufacturing. A measurement model and structural model will be tested using PLS-SEM. The software, smart PLS 3.2.8, and statistical package for social sciences (SPSS) version 24 will be used for data analysis. The SPSS software will be used for descriptive analysis. 


\section{Conclusion}

Maximizing the available resources (man, machine, method, and material) is the key factor for managers to improve the profitability of the company. Globalization in most industries has sparked heightened awareness of the various risks and vulnerabilities that products are exposed to as they move along the supply chain link from design and sourcing to manufacturing, transportation, distribution and final sale to the consumer. The chain of supply networks is long and complex (Kamble, Gunasekaran, \& Gawankar, 2018; Richardson, 2015). The purpose of this research is to examine the impact of outsourcing activities on organizational performance with the mediating effect of integrity capabilities. Finding of this research likely to be useful for managers for deciding or managing outsourcing activity.

Furthermore, this research is expected to give knowledge to the organization on understanding the impact of outsourcing activities and their effect on organization performance. The knowledge will be useful in understanding the importance of supply chain management for successful outsourcing activity that meet the organization objective mainly on cost reduction and improvement of core function for business sustainability and growth. This research can be used as a guide for the future researcher or organizations that are facing problems related to outsourcing activities and can benefit government agencies. Finally, when this study is concluded, it will be able to assess the hypothesized relationships described in this paper and consequently be able to provide detailed research and practical implications, including suggestions for future research agendas. Furthermore, the finding will be able to shed lights on the establishment of integrity capabilities and its impact on the company's performance.

\section{Acknowledgement}

We would like to thank Yayasan Bank Rakyat for the financial support by sponsoring this paper to be presented in the FGIC $2^{\text {nd }}$ Conference on Governance and Integrity 2019.

\section{References}

[1] Ahi, P., Jaber, M. Y., \& Searcy, C. (2016). A comprehensive multidimensional framework for assessing the performance of sustainable supply chains. Applied Mathematical Modelling, 40, 10153-10166. 
[2] Ahmad, F., Mohammad, I., Maidin, S. L., Zainol, R., \& Noor, N. M. (2013). Malaysian Development Plan System: Issues And Problems, One Decade After Its Reform (20012011). Journal of the Malaysian Institute of Planners, 9, 1-20.

[3] Allur, E., Heras-Saizarbitoria, I., Boiral, O., Testa, F., Allur, E., Heras-Saizarbitoria, I., ... Testa, F. (2018). Quality and Environmental Management Linkage: A Review of the Literature. Sustainability, 10, 4311.

[4] Biesenthal, C., Clegg, S., Mahalingam, A., \& Sankaran, S. (2018). Applying institutional theories to managing megaprojects. International Journal of Project Management, $36,43-54$.

[5] Bigliardi, B., \& Bottani, E. (2010). Performance measurement in the food supply chain: a balanced scorecard approach. Facilities, 28, 249-260.

[6] Cherrafi, A., Elfezazi, S., Chiarini, A., Mokhlis, A., \& Benhida, K. (2016). The integration of lean manufacturing, Six Sigma and sustainability: A literature review and future research directions for developing a specific model. Journal of Cleaner Production, $139,828-846$.

[7] Dash Wu, D., Yang, L., \& Olson, D. L. (2018). Green supply chain management under capital constraint. International Journal of Production Economics, 1-8.

[8] Deloitte. (2016). Competitive Index 2016. Retrieved from https://www2.deloitte.com/ GlobalOutsourcingSurvey

[9] Department of Statistics Malaysia. (2018a). Gross Domestic Product 2017.

[10] Department of Statistics Malaysia. (2018b). Index of Industrial Production.

[11] Dissanayake, C. K., \& Cross, J. A. (2018). Systematic mechanism for identifying the relative impact of supply chain performance areas on the overall supply chain performance using SCOR model and SEM. International Journal of Production Economics, 201, 102-115.

[12] Federation of Malaysian Manufacturing. (2017). FMM Directory: Malaysian Industries.

[13] Fernando, Y., Wah, W. X., \& Shaharudin, M. S. (2016). Does a firm's innovation category matter in practising eco-innovation? Evidence from the lens of Malaysia companies practicing green technology. Journal of Manufacturing Technology Management, 27, 208-233.

[14] Fernando, Yudi, Jasmi, M. F. A., \& Shaharudin, M. S. (2019). Maritime green supply chain management: its light and shadow on the bottom line dimensions of sustainable business performance. International Journal of Shipping and Transport Logistics, 11, 60-93. 
[15] Fu, Y., Kok, R. A. W., Dankbaar, B., Ligthart, P. E. M., \& van Riel, A. C. R. (2018). Factors affecting sustainable process technology adoption: A systematic literature review. Journal of Cleaner Production, 205, 226-251.

[16] Galankashi, M. R., Memari, A., Anjomshoae, A., Ma’aram, A., \& Helmi, S. A. (2014). Selection of Supply Chain Performance Measurement. International Journal of Industrial Engineering and Management, 5, 131-137.

[17] Giovanni, P. De. (2012). Do internal and external environmental management contribute to the triple bottom line? International Journal of Operations \& Production Management, 32, 265-290.

[18] Gunasekaran, A., Subramanian, N., \& Ngai, E. W. T. (2019). Quality management in the 21st century enterprises: Research pathway towards Industry 4.0. International Journal of Production Economics, 207, 125-129.

[19] Gunasekaran, Angappa, \& Ngai, E. W. T. (2012). The future of operations management: An outlook and analysis. International Journal of Production Economics, 135, 687-701.

[20] Gunasekaran, Angappa, Subramanian, N., \& Rahman, S. (2015). Green supply chain collaboration and incentives: Current trends and future directions. Transportation Research Part E: Logistics and Transportation Review, 74, 1-10.

[21] Hassan, M. G., Razali, M. R., \& Talib, A. N. A. (2015). The impact of industrial suppliermanufacturer relationship on strategic outsourcing success. Jurnal Teknologi, 74, 83-90.

[22] Helmi Ali, M., Hua Tan, K., \& Daud Ismail, M. (2017). British Food Journal A supply chain integrity framework for halal food) "A supply chain integrity framework for halal food" A supply chain integrity framework for halal food. British Food Journal British Food Journal Iss Journal of Islamic Marketing Iss, 119, 20-38.

[23] Huo, B., Ye, Y., Zhao, X., \& Shou, Y. (2016). The impact of human capital on supply chain integration and competitive performance. International Journal of Production Economics, 178, 132-143.

[24] Jabbour, A. B. L. D. S., Frascareli, F. C. D. O., \& Jabbour, C. J. C. (2015). Green supply chain management and firms' performance: Understanding potential relationships and the role of green sourcing and some other green practices. Resources, Conservation and Recycling, 104, 366-374.

[25] Jasmi, M. F. A., \& Fernando, Y. (2018). Drivers of maritime green supply chain management. Sustainable Cities and Society, 43, 366-383. 
[26] Kamalahmadi, M., \& Parast, M. M. (2016). A review of the literature on the principles of enterprise and supply chain resilience: Major findings and directions for future research. International Journal of Production Economics, 171, 116-133.

[27] Kamble, S. S., Gunasekaran, A., \& Gawankar, S. A. (2018). Sustainable Industry 4. 0 framework: A systematic literature review identifying the current trends and future perspectives. Process Safety and Environmental Protection, 117, 408-425.

[28] Karim, M. A., Smith, A. J. R., Halgamuge, S. K., \& Islam, M. M. (2008). A comparative study of manufacturing practices and performance variables. International Journal of Production Economics, 112, 841-859.

[29] Li, J., Su, Q., \& Ma, L. (2017). Production and transportation outsourcing decisions in the supply chain under single and multiple carbon policies. Journal of Cleaner Production, 141, 1109-1122.

[30] Liu, Y., Blome, C., Sanderson, J., \& Paulraj, A. (2018). Supply chain integration capabilities, green design strategy and performance: a comparative study in the auto industry. Supply Chain Management: An International Journal. doi:10.1108/SCM-032018-0095

[31] Nishitani, K., Kokubu, K., \& Kajiwara, T. (2013). Low-carbon supply chain management and its performance in Japanese manufacturing firms Low-carbon supply chain management and its performance in Japanese manufacturing firms.

[32] Padhi, S. S., Pati, R. K., \& Rajeev, A. (2018). Framework for selecting sustainable supply chain processes and industries using an integrated approach. Journal of Cleaner Production, 184, 969-984.

[33] Richardson, L. (2015). Performing the sharing economy. Geoforum, 67, 121-129.

[34] Rusli, K. A., Rahman, A. A., \& Ho, J. A. (2012). Green Supply Chain Management in Developing Countries: A Study of Factors and Practices in Malaysia. In UMT 11th International Annual Symposium on Sustainability Science and Management (pp. 278-285).

[35] Saeidi, S. P., Sofian, S., Saeidi, P., Saeidi, S. P., \& Saaeidi, S. A. (2015). How does corporate social responsibility contribute to firm financial performance? The mediating role of competitive advantage, reputation, and customer satisfaction. Journal of Business Research, 68, 341-350.

[36] Shaharudin, M. S., \& Fernando, Y. (2015). Low Carbon Footprint: The Supply Chain Agenda in Malaysian Manufacturing Firms. Promoting Sustainable Practices through Energy Engineering and Asset Management, 324-347.

[37] Shi, X., Si, B., Zhao, J., Tian, Z., Wang, C., Jin, X., \& Zhou, X. (2019). Magnitude, Causes, and Solutions of the Performance Gap of Buildings: A Review. Sustainability, 11, 937. 
[38] Srinivasan, R., Giannikas, V., Kumar, M., Guyot, R., \& McFarlane, D. (2018). Modelling food sourcing decisions under climate change: A data-driven approach. Computers \& Industrial Engineering, 1-9.

[39] Tosarkani, B. M., \& Amin, S. H. (2018). A multi-objective model to configure an electronic reverse logistics network and third party selection. Journal of Cleaner Production, 198, 662-682.

[40] Wang, Q., \& He, L. (2018). Managing risk aversion for low-carbon supply chains with emission abatement outsourcing. International Journal of Environmental Research and Public Health, 15. doi:10.3390/ijerph15020367

[41] Xiao, Y., Yang, S., Zhang, L., \& Kuo, Y. H. (2016). Supply chain cooperation with price-sensitive demand and environmental impacts. Sustainability (Switzerland), 8. doi:10.3390/su8080716

[42] Yin, H., Zhao, J., Xi, X., \& Zhang, Y. (2018). Evolution of regional low-carbon innovation systems with sustainable development: An empirical study with big-data. Journal of Cleaner Production, 209, 1545-1563.

[43] Zhang, B., Wang, Z., Yin, J., \& Su, L. (2012). CO 2 emission reduction within Chinese iron \& steel industry: practices, determinants and performance. Journal of Cleaner Production, 33, 167-178.

[44] Zhao, Z. Y., Zhao, X. J., Davidson, K., \& Zuo, J. (2012). A corporate social responsibility indicator system for construction enterprises. Journal of Cleaner Production, 29-30, 277-289.

[45] Zhu, Q., Sarkis, J., \& Lai, K. (2013). Institutional-based antecedents and performance outcomes of internal and external green supply chain management practices. Journal of Purchasing and Supply Management, 19, 106-117. 